\title{
Socioeconomic and Demographic Factors Patterning Smokeless Tobacco Use Behavior in Bangladesh: A Cross-Sectional Multilevel Analysis
}

\section{Munjila Begum and Papia Sultana*}

Department of Statistics, University of Rajshahi, Rajshahi, Bangladesh

\begin{abstract}
Background: Smokeless tobacco is also highly addictive and causes cancer of the head and neck, esophagus and pancreas, besides many oral diseases. Bangladesh is one of the most prevalent smokeless tobacco consumption countries in the world. This paper aimed to examine the socioeconomic and demographic factors patterning smokeless tobacco consumption among adults aged 15 years and above in Bangladesh using multilevel analysis.
\end{abstract}

Materials and methods: A cross sectional, nationally representative sample of individuals from the Global Adult Tobacco Survey in Bangladesh (2010), which covered 9629 individuals aged 15 years and above using multi-stage stratified cluster sampling has been analyzed. Smokeless tobacco use daily was considered as outcome variable. Multilevel logistic regression analysis has been used with individuals nested within clusters. Measures of association (odds ratio) and measures of variance (intra-class correlation (ICC)) have been calculated, as well as the discriminatory accuracy by calculating the area under the ROC curve (AUC). Also the comparison between single and multilevel model has been done to investigate the necessity of multilevel effects.

Results: According to the multilevel logistic regression model female use smokeless tobacco more than male (odds ratio (OR): $1.72,95 \% \mathrm{Cl}: 1.39,2.07)$. The use of smokeless tobacco by age was highest among older group (>46 years) than youngest group ( $\leq 24$ years) (OR: $16.04,95 \% \mathrm{Cl}$ : 12.60, 20.53). The smokeless tobacco use was highest among the least educated (no formal education) $(\mathrm{OR}=4.93,95 \% \mathrm{Cl}: 3.28,7.41)$ compared to highest educated (college/university completed or above) respondent. Respondents from the poorest wealth index were significantly more likely to consume smokeless tobacco (OR $1.67,95 \% \mathrm{Cl}: 1.33,2.09)$ compared to respondents of richest wealth index.

Conclusions: There is an urgent need to curb the use of smokeless tobacco among female, less educated, older and of lowest wealth index. Tobacco control policies in Bangladesh should adopt a targeted, population-based approach to control and reduce tobacco consumption considering of socioeconomic and demographic factors to make it successful in the country.

Keywords: GATS; Smokeless tobacco; Cluster; Multilevel logistic regression; AUC; AIC; BIC

\section{Introduction}

Tobacco use is one of the vulnerable primary causes of premature death and disability in the world. It is observed that at least 4.9 million deaths occur annually due to tobacco and the figure is expected to rise to about 10 million by 2030 [1]. This means that tobacco will cause more deaths in the next 10 years from now than malaria, tuberculosis, maternal and major childhood diseases all together and 70 percent of these tobacco related deaths are expected to take place in the developing countries. Tobacco use usually starts in adolescence and continues into adult life, meaning that much tobacco's future victims are today's children. Tobacco consumption is very injurious for health. Causation premature death occurred through smoking related illness such as lung cancer and cardiovascular disease. Tobacco is also accountable for substantial heath care costs and lost productivity due to illness and premature death [2]. Bangladesh is one of the largest tobacco consuming countries in the world, either smoked or smokeless product. Over $58 \%$ of men and $29 \%$ of women use some form of tobacco. In 2012, an estimated 46.3 million adults used some form of tobacco product, smoked or smokeless. Most smokers are male-28.3\% of adult men smoke manufactured cigarettes and $21.4 \%$ smoke bidis. In contrast, smokeless tobacco use is substantial across both genders, with $26.4 \%$ of men and $27.9 \%$ of women using some form of smokeless tobacco. Most smokeless tobacco use is of betel quid with tobacco (zarda) though other forms of smokeless tobacco products, including gul, sada pata, and khoinee, are also commonly used [3,4]. Smokeless tobacco use is also associated with the increasing risk of cancer.
Smokeless tobacco is also highly addictive and causes cancer of the head and neck, esophagus and pancreas, besides many oral diseases [2].

Currently, researchers are giving priority to tobacco use as research topic and some researches also have been done on tobacco in Bangladesh. Most of them are to investigate the prevalence and predictors of tobacco smoking [5-12]. Very few works have done on smokeless tobacco use in Bangladesh [13,14]. Therefore, the present paper examines predictors of smokeless tobacco use in Bangladesh using multilevel analysis and to explore the true effect of these predictors. Emphasis is given to compare the estimates (odds ratios) obtained using simple logistic and multilevel logistic regression model. An attempt has also been made to make proper policies and implications on the basis of the findings.

\section{Methods}

This study is based on the secondary data collected by the Global Adult Tobacco Survey (GATS) 2009-10 [15]. The survey data was

*Corresponding author: Papia Sultana, Department of Statistics, University of Rajshahi, Rajshahi, Bangladesh, Tel: 880721 750244; E-mail: papia.stat@ru.ac.bd

Received August 27, 2018; Accepted September 17, 2018; Published September 21, 2018

Citation: Begum M, Sultana P (2018) Socioeconomic and Demographic Factors Patterning Smokeless Tobacco Use Behavior in Bangladesh: A Cross-Sectional Multilevel Analysis. J Biom Biostat 9: 411. doi: 10.4172/2155-6180.1000411

Copyright: ( $) 2018$ Begum M, et al. This is an open-access article distributed under the terms of the Creative Commons Attribution License, which permits unrestricted use, distribution, and reproduction in any medium, provided the original author and source are credited. 
released for the general researchers by International Institute for Population Sciences. Global Adult Tobacco Survey is the global standard for systematically monitoring adult tobacco use (smoking and smokeless) and tracking key tobacco control indicators. GATS are conducted globally in 14 countries. The Centers for Disease Control and Prevention (CDC), CDC Foundation, Johns Hopkins Bloomberg School of Public Health (JHSPH), Research Triangle Institute International (RTI International), the World Health Organization and many countries throughout the world worked together to design and implement GATS. For each participating country, a standard protocol with respect to questionnaire, sample design, data collection and management procedures was used. Survey information was collected using handheld devices. GATS-Bangladesh (2009-10) is a nationally representative household survey covering population aged 15 years and above. The sampling frame used for GATS Bangladesh design was the population census of the People's Republic of Bangladesh conducted by Bangladesh Bureau of Statistic (BBS) in 2001. The survey was based on a three-stage stratified cluster sample of households (Figure 1). At the first stage 400 Primary Sampling Units (PSUs) (Mauza in

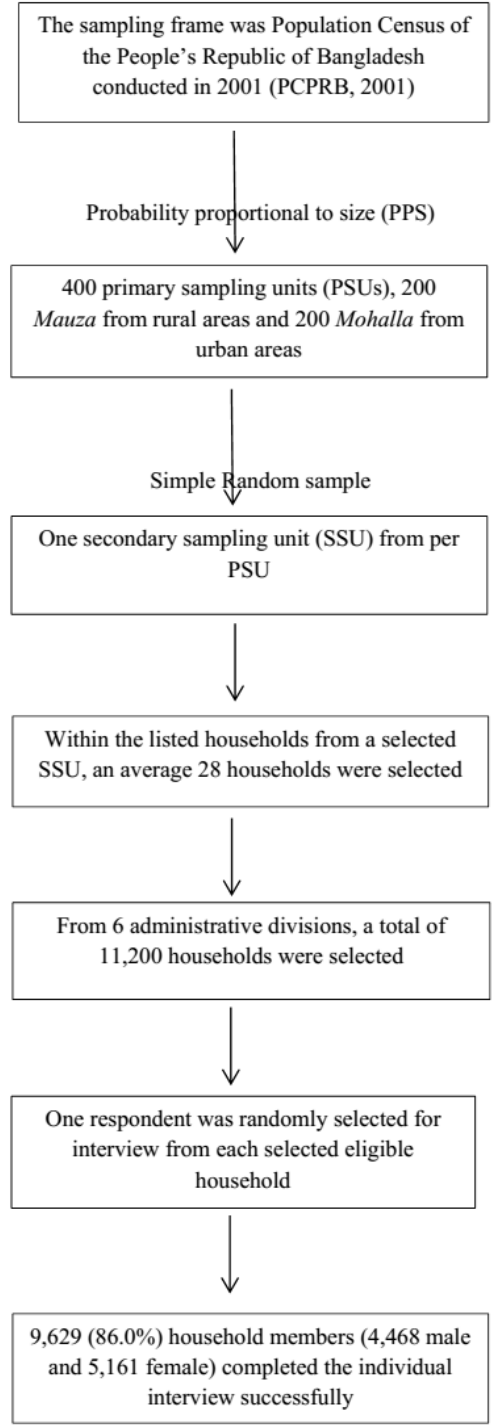

Figure 1: Study design of Global Adult Tobacco Survey in Bangladesh, 2010. rural and Mohalla in urban areas) were selected with probability proportional to size (PPS), followed by a random selection of one Secondary Sampling Unit (SSU) per selected PSU. At the third stage households were selected systematically within the listed households from a selected SSU. SSUs were based upon Enumeration Areas (EA) from the Bangladesh Agricultural Census conducted in 2008. These selected EAs were updated with mapping and listing. Typically these EAs consisted of 200 household units in Mauzas and 300 household units in each Mohalla. The explicit stratification used at the first stage of selection based upon urban (Mohalla) and rural (Mauza) designation of Bangladesh Bureau of Statistics (BBS). Each list of rural and urban geopolitical units was implicitly stratified by division, and within division by the percent literacy of women in each Mohalla and Mauza. Following the standard protocol of GATS, the initial target was a representative sample of 8000 non-institutionalized households subject to the applicable non-response and eligibility rates (a target sample of 2000 households each in urban, rural, male and female subgroups). Sample design for Bangladesh consists of 400 PSUs, 200 in urban areas and 200 in rural areas. After accounting for possible non response and eligibility rates, it was determined to have an average of 28 households (later randomized to produce equal male and female households based on design specifications) per selected SSU resulting in a total sample size of 11200 non institutionalized households from all 6 administrative divisions. As per design, one respondent was randomly selected for the interview from each selected eligible household to participate in the survey. Details can be found in previous published paper [16-19]. There were total of 9629 completed interviews (male $=4468$ and female $=5161$ ). The term 'current smokeless tobacco users' includes smokeless tobacco product users 'daily' basis in this paper (Figure 2).

First descriptive analysis has been performed to know the characteristics of study subjects. Association of various cofactors with smokeless tobacco use has been analyzed using chi-square test (Pearson or likelihood ratio whichever applicable). To determinate smokeless tobacco use multilevel logistic regression model $[20,21]$ has been used for studying tobacco use behavior. Maximum likelihood (ML) estimation method has been used to estimate the parameters of multilevel model. Akaike's information criterion (AIC) and Bayesian information criterion (BIC) have been used to compare competing models. Deviance information criterion (DIC) statistic also has been used as an indicator of model fit. Models having smaller DIC are favored. The multilevel process was stepwise. The first step examined the null model of overall probability of smokeless tobacco use without adjustment for predictors. Second step included first the univariate analysis (both single and multilevel), and then random slop multilevel univariate analysis for each of the selected explanatory variables. Third step considered a model building for two-level multiple logistic regression analyses including single level multiple analysis. The fit for all models has been assessed using the AUC [22]. Intra-class correlation (ICC) has been used as a measure for describing reliability and validity within the set of data. If the ICC approaches 0 then the grouping by counties or entities are of no use. If the ICC approaches 1 then there is no variance to explain at the individual level. The dependent variable in the analysis is current smokeless tobacco use (daily). The explanatory variables considered for this analysis include sex, age, education (level of education), work status and wealth index (WI). Clusters (i.e, PSUs) have been considered as another source of variation (random effect) besides individual respondents for the multilevel (two-level) logistic regression model. All analyses have been carried out using Stata version 13.0.

\section{Analytical Results}

Characteristic of study subjects has been summarized in Table 1. It has been found that $21.93 \%$ of adult male and $26.17 \%$ of adult female 
Citation: Begum M, Sultana P (2018) Socioeconomic and Demographic Factors Patterning Smokeless Tobacco Use Behavior in Bangladesh: A Cross-Sectional Multilevel Analysis. J Biom Biostat 9: 411. doi: 10.4172/2155-6180.1000411

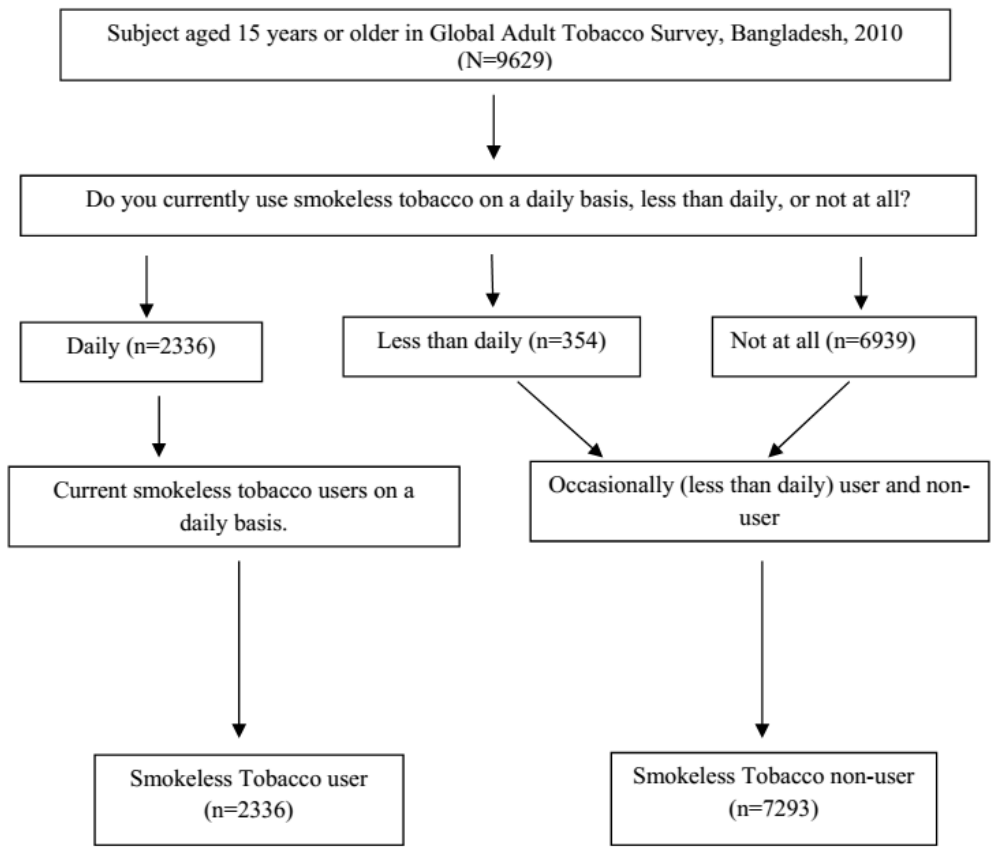

Figure 2: Data screening process to select current smokeless tobacco user in Bangladesh.

\begin{tabular}{|c|c|c|c|}
\hline Socio-economic and demographic status & Total respondent $(\mathrm{N}=9629)$ & Smokeless tobacco user $(\mathbf{N}=\mathbf{2 3 3 6})$ & P-value* \\
\hline \multicolumn{4}{|l|}{ Residence } \\
\hline Urban & $4,857(50.44)$ & $978(41.87)$ & \multirow[t]{2}{*}{$<0.001$} \\
\hline Rural & $4,772(49.56)$ & $1,358(58.13)$ & \\
\hline \multicolumn{4}{|l|}{ Gender } \\
\hline Male & $4,468(46.40)$ & $980(41.95)$ & \multirow[t]{2}{*}{$<0.001$} \\
\hline Female & $5,161(53.60)$ & $1,356(58.05)$ & \\
\hline \multicolumn{4}{|l|}{ Age (yrs) } \\
\hline$\leq 24$ & $2,073(21.53)$ & $96(4.11)$ & \multirow[t]{4}{*}{$<0.001$} \\
\hline $25-34$ & $2,665(27.68)$ & $421(18.02)$ & \\
\hline $35-44$ & $2,537(26.35)$ & $774(33.13)$ & \\
\hline$\geq 45$ & $2,354(24.45)$ & $1,045(44.73)$ & \\
\hline \multicolumn{4}{|l|}{ Level of Education } \\
\hline No formal schooling & $3,416(35.48)$ & $1,318(57.08)$ & \multirow[t]{7}{*}{$<0.001$} \\
\hline Less than primary school completed & $1,487(15.44)$ & $366(15.85)$ & \\
\hline Primary school completed & $1,115(11.58)$ & $254(11.00)$ & \\
\hline Less than secondary school completed & $1,937(20.12)$ & $243(10.52)$ & \\
\hline Secondary school completed & $663(6.89)$ & $61(2.64)$ & \\
\hline High school completed & $463(4.81)$ & $29(1.26)$ & \\
\hline College completed or higher & $484(5.03)$ & $38(1.65)$ & \\
\hline \multicolumn{4}{|l|}{ Work status } \\
\hline Employee (Govt. Non-Govt.) & $961(9.99)$ & $141(6.04)$ & \multirow[t]{7}{*}{$<0.001$} \\
\hline Business (small/large) & $993(10.31)$ & $212(9.08)$ & \\
\hline Farming (land owner and farmer) & $826(8.58)$ & $239(10.23)$ & \\
\hline Agri or industrial worker/daily labour/other self employed & $1527(15.95)$ & $410(17.55)$ & \\
\hline homemaker/housework & $4030(41.85)$ & $1,067(45.68)$ & \\
\hline Retired and unemployed (able/unable to work) & $427(4.43)$ & $130(5.57)$ & \\
\hline Student/Others & $855(8.89)$ & $137(5.86)$ & \\
\hline \multicolumn{4}{|l|}{ Wealth Index } \\
\hline Poorest & $1,923(19.97)$ & $638(27.31)$ & \multirow[t]{5}{*}{$<0.001$} \\
\hline Poor & $2,040(21.19)$ & $582(24.91)$ & \\
\hline Middle & $1,732(17.99)$ & $424(18.15)$ & \\
\hline Rich & $2,068(21.48)$ & $438(18.75)$ & \\
\hline Richest & $1,866(19.38)$ & $254(10.87)$ & \\
\hline
\end{tabular}

Table 1: Characteristic of study subjects. 
Citation: Begum M, Sultana P (2018) Socioeconomic and Demographic Factors Patterning Smokeless Tobacco Use Behavior in Bangladesh: A Cross-Sectional Multilevel Analysis. J Biom Biostat 9: 411. doi: 10.4172/2155-6180.1000411

Page 4 of 6

use any form of smokeless tobacco product daily. Results for test of association between current smokeless tobacco use (daily) and each of the explanatory variables have been summarized in Table 1, too. All explanatory variables are found to be highly statistically associated with current smokeless tobacco use ( $\mathrm{p}$-value $<0.001)$.

An intercept-only model that predicts the probability of smokeless tobacco use has been fitted, next. Table 2 represents the odds ratio and standard error of single level and multilevel logistic regression model.
The ML estimate from the single level logistic model of the ratio of smokeless tobacco user to smokeless tobacco nonuser is 0.32 . It is in fact odds-ratio when no predictors have been considered in the model. In comparison, the same ratio is estimated to be 0.289 , from the multilevel model by the adaptive Gauss-Hermite quadrature methods respectively. Compared to the odds ratios obtained by multilevel method the standard logistic model odds-ratio has been overestimated. It is observed that there is a significant difference between the standard

\begin{tabular}{|c|c|c|c|c|}
\hline \multirow{3}{*}{$\begin{array}{l}\text { Model effect } \\
\text { Fixed effect } \\
\text { Intercept }\end{array}$} & \multicolumn{2}{|c|}{ Single level logistic regression } & \multicolumn{2}{|c|}{ Multilevel logistic regression } \\
\hline & S.E. & Odds ratio & S.E. & Odds ratio \\
\hline & 0.008 & 0.320 & 0.01 & 0.289 \\
\hline $\begin{array}{l}\text { Random effect } \\
\text { Intercept (level-2), var (S.E.) } \\
\text { ICC (\%) }\end{array}$ & \multicolumn{2}{|c|}{-} & \multicolumn{2}{|c|}{$\begin{array}{c}0.42(0.05)^{\star \star} \\
11.42\end{array}$} \\
\hline$-2 \log \mathrm{L}($ Deviance) & \multicolumn{2}{|c|}{10670.07} & \multicolumn{2}{|c|}{10393.94} \\
\hline
\end{tabular}

Table 2: Odds ratio and standard errors of an intercept-only logit model and intercept-only multilevel models predicting the probability of smokeless tobacco use.

\begin{tabular}{|c|c|c|c|c|}
\hline \multirow[t]{2}{*}{ Socio-economic and demographic correlates } & Simple logistic regression & Multilevel logistic regression & \multirow{2}{*}{$\begin{array}{l}\text { Odds ratio } \\
\text { difference }\end{array}$} & \multirow{2}{*}{$\begin{array}{c}\text { Over/Under } \\
\text { Estimation (\%) }\end{array}$} \\
\hline & OR $(95 \% \mathrm{Cl})$ & OR $(95 \% \mathrm{Cl})$ & & \\
\hline \multicolumn{5}{|l|}{ Gender } \\
\hline Male (RC) & 1.00 & 1.00 & & \\
\hline Female & $1.70(1.41-2.05)$ & $1.72^{\star *}(1.39,2.07)$ & -0.02 & 1.17 \\
\hline \multicolumn{5}{|l|}{ Age (yrs) } \\
\hline$\leq 24(\mathrm{RC})$ & 1.00 & 1.00 & - & - \\
\hline $25-34$ & $3.61 * *(2.85-4.57)$ & $3.73^{* *}(2.93,4.75)$ & -0.12 & 3.32 \\
\hline $35-45$ & $8.48^{\star \star}(6.72-10.71)$ & $9.09^{* *}(7.16,11.54)$ & -0.61 & 7.19 \\
\hline$\geq 46$ & $14.72^{* *}(11.61-18.64)$ & $16.09^{* *}(12.60,20.53)$ & -1.37 & 9.30 \\
\hline \multicolumn{5}{|l|}{ Level of Education } \\
\hline College/University completed or higher (RC) & 1.00 & 1.00 & & \\
\hline High school completed & $1.04(0.62-1.75)$ & $1.08(0.63,1.83)$ & -0.04 & 3.85 \\
\hline Secondary school completed & $1.61^{*}(1.03-2.50)$ & $1.71^{*}(1.08,2.71)$ & -0.1 & 6.21 \\
\hline Less than secondary school completed & $2.23^{* *}(1.51-3.28)$ & $2.32^{* *}(1.55,3.49)$ & -0.09 & 4.04 \\
\hline Primary school completed & $3.75^{\star *}(2.52-5.59)$ & $3.91^{* *}(2.57,5.95)$ & -0.16 & 4.27 \\
\hline Less than primary school completed & $3.38^{* *}(2.28-5.02)$ & $3.61^{* *}(2.38,5.46)$ & -0.23 & 6.80 \\
\hline No formal schooling & $4.37^{* *}(2.96-6.44)$ & $4.93^{* *}(3.28,7.41)$ & -0.56 & 12.81 \\
\hline \multicolumn{5}{|l|}{ Work status } \\
\hline Employee (Govt. Non-Govt.) (RC) & 1.00 & 1.00 & & \\
\hline Business (small/large) & $0.97(0.75-1.27)$ & $0.92(0.70,1.21)$ & 0.05 & 5.15 \\
\hline Farming (land owner and farmer) & $0.84(0.64-1.11)$ & $0.83(0.63,1.12)$ & 0.01 & 1.19 \\
\hline Agri or industrial worker/daily labour/other self employed & $0.88(0.69-1.13)$ & $0.82(0.64,1.09)$ & 0.06 & 6.82 \\
\hline homemaker/housework & $0.72(0.56-0.94)$ & $0.71(0.54,0.94)$ & 0.01 & 1.39 \\
\hline Retired and unemployed (able/unable to work) & $0.83(0.60-1.14)$ & $0.77(0.55,1.08)$ & 0.06 & 7.23 \\
\hline Student/Other (Specify) & $1.12(0.83-1.51)$ & $0.95(0.69,1.31)$ & 0.17 & 15.18 \\
\hline \multicolumn{5}{|l|}{ Wealth Index } \\
\hline Richest (RC) & 1.00 & 1.00 & & \\
\hline Rich & $1.36^{*}(1.09-1.61)$ & $1.32^{*}(1.07,1.63)$ & 0.04 & 2.94 \\
\hline Middle & $1.39 * *(1.12-1.70)$ & $1.33^{* *}(1.07,1.66)$ & 0.06 & 4.31 \\
\hline Poor & $1.64^{\star *}(1.33-2.02)$ & $1.54^{* *}(1.23,1.92)$ & 0.1 & 6.09 \\
\hline Poorest & $1.79 * *(1.44-2.21)$ & $1.67^{\star *}(1.33,2.09)$ & 0.12 & 6.70 \\
\hline Cluster variance & & $0.374^{* *}(\mathrm{SE}=0.051)$ & & \\
\hline No. of observation & & 9565 & & \\
\hline No. of cluster & & 399 & & \\
\hline Intraclass Correlation (ICC, \%) & & 10.2 & & \\
\hline AUC & 0.773 & 0.8187 & & \\
\hline Log-likelihood & -4433.1712 & -4349.7236 & & \\
\hline AIC & 8907.136 & 8743.447 & & \\
\hline $\mathrm{BIC}$ & 9043.287 & 8901.096 & & \\
\hline DIC & 8869.136 & 8699.447 & & \\
\hline
\end{tabular}

Table 3: Identifying correlates of smokeless tobacco use in Bangladesh using multilevel logistic regression analysis. 
logistic estimate and the multilevel logistic estimate. Obtained result shows that the random effects i.e. the cluster specific effects are significant. Therefore, failing to take into account the standard logistic model has overestimated the odds-ratio by $11 \%$ when multilevel model by corresponding methods adaptive Gauss-Hermite quadrature has been applied (Table 2).

In the multilevel logistic model units at lower level (level-1) are individual's (respondents aged 15 and above) who are nested within units at higher level (clusters, 400 PSUs at level-2). The model is followed with all the significant factors to assess their simultaneous effect on smokeless tobacco use. The ICC is 0.10 (Table 3), which indicates 10 percent of the total variance in smokeless tobacco use is explained at the cluster-level. It is observed that there exist significant differences between the odds ratios of these two models for each of the explanatory variables. Table 3 presents odds ratios and 95\% CI from a single level logistic model predicting the probability of smokeless tobacco use and its equivalent from multilevel model. The last two columns of Table 3 represent respectively the difference in odds ratio between single and multilevel multivariate models and percentage of under or overestimation of odds ratio by single level modeling. Female respondents were 1.72 times more likely to use smokeless tobacco product than males. The multilevel effect is not observed notably for predictor gender. The odds ratio under single level model is slightly overestimated $(1.17 \%)$ compared to multilevel estimates. The multilevel model shows that the probability of using smokeless tobacco increases significantly with age, adjusting for the effect of other predictors and respondents of age greater than 45 are 16.1 times more likely to use smokeless tobacco product than youngest group (age $\leq 24$ years), whereas under the single level model the corresponding odds is 14.7 times higher. Thus the odds ratio has also underestimated significantly by about $9.30 \%$. Level of education seems to be another significant influential factor in regulating smokeless tobacco use except for the highest level of education (college/university completed or higher). Among the respondents who have no formal schooling and less than primary education, the respective odds of using smokeless tobacco is about 4.93 times and 3.61 times higher compared to the odds of smokeless tobacco use among respondents with highest level of education (college/university completed or higher) for the multilevel model, whereas under the single level model the corresponding odds ratio are 4.37 times and 3.38 times higher, respectively.

It is also found that work status is not a significant predictor of smokeless tobacco use. Results reveal that wealth index (WI) or respondent's economic status is another significant correlates of smokeless tobacco use. The probability of smokeless tobacco use is low among the respondents who are from economically well off families. The multilevel analysis shows that the respondents from middle, poor and poorest economic status have OR of smokeless tobacco use $33 \%$, $54 \%$ and $67 \%$ higher compared to the odds among richest group of respondents. The corresponding figures under single level model are about $39 \%, 64 \%$ and $79 \%$. Thus for wealth index the odds ratios of middle, poor and poorest group have been overestimated respectively by $4.31 \%, 6.09 \%$ and $6.70 \%$. Thus it is evident that if multilevel effect is not taken into account in the model, the estimates would be either underestimated or overestimated considerably. These results imply that single-level model for this data set should not be considered. Also multilevel model performs better than single level model. The ROC analysis demonstrated a high level of predictive accuracy, with an area under the ROC curve (AUC) of 0.8187 for multilevel model whereas AUC is 0.773 for single level model (Figure 3 and Table 3). Also, Comparing AIC and BIC statistics (Table 3 ) it is confirmed that the

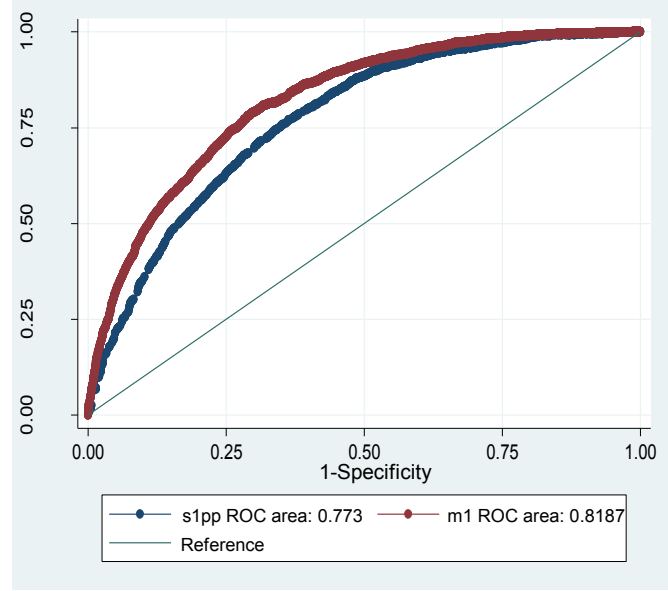

Figure 3: Area under ROC curve (AUC) for predicting use of smokeless tobacco plotted for separately for simple logistic regression model (Blue thick line) and for multilevel model (Red thick line) which adjusted for sex, age, education, occupation, wealth index. The diagonal line represents an AUC equal to 0.50 .

multilevel logistic regression model is preferable to the simple logistic regression model.

\section{Discussion}

The GATS 2010 data is based on multistage stratified cluster [23]. This study found that for such hierarchical structured data the multilevel effects have been found to be significant and have to be taken into consideration in logistic regression modeling which leads multilevel logistic regression modeling. As a result, this multilevel analysis enables the proper investigation of the effects of all explanatory variables measured at cluster levels on the response variable- smokeless tobacco use (daily). The main reason for which there exist significant multilevel effects for the data might be that there existed dependencies between individual observations due to simple random sampling was not taken but cluster sampling from geographical areas was used instead. This study explored the associations of individual and cluster level factors with smokeless tobacco using a multilevel analytical framework.

The multilevel analysis of this study revealed that the mean effect of each of the predictors over current smokeless tobacco use daily, viz., sex, age (group), education, wealth index varied much significantly ( $p$-value $<0.001$ ) in cluster level. Smokeless tobacco use in Bangladesh has been strongly influenced by socio-demographic and socioeconomic status. Female are more likely to use smokeless tobacco than male. Smokeless tobacco use increases as age increases. People who had no formal schooling are about four times more likely to use smokeless tobacco compared to those who had completed college/university or higher. This study did not find any association between work status and smokeless tobacco use. The primary motivation for this study, however, was to investigate true variability in smokeless tobacco using behavior across socioeconomic and demographic characteristics. With regard to decreasing the smokeless tobacco use rate, there are a number of conclusions and strategic implications that flow from these findings. It is necessary to create a greater awareness among 15 and above aged people of Bangladesh of the issues which are found to effect smokeless tobacco use prevalence significantly. All opportunities should be considered to educate them about the adverse effect of smokeless 
Citation: Begum M, Sultana P (2018) Socioeconomic and Demographic Factors Patterning Smokeless Tobacco Use Behavior in Bangladesh: A Cross-Sectional Multilevel Analysis. J Biom Biostat 9: 411. doi: 10.4172/2155-6180.1000411

tobacco use. Hence it should be needed to provide counselling to men in addition to women.

The main strengths of the study are the nationally representative population-based survey and the coverage of both male and female including urban and rural areas. Interestingly very few of the earlier studies had captured comprehensive information on use of smokeless tobacco, the present study provides results related to the use of smokeless tobacco across various demographic subgroups and identified important predictors such as education and socioeconomic status that may have bearing on public health policy. In Bangladesh, tobacco control legislation at present does not cover smokeless tobacco, and thus it may prove beneficial to include smokeless tobacco into tobacco policies addressing marketing, packaging, sales and in effective educational or media campaigns to educate the public about harmful effects of using smokeless tobacco.

The cross-sectional nature of the data does not allow us to assess the trends in smokeless tobacco consumption over time or to make causal inferences about the associations observed. Data were also based on self-reports so the validity of the responses may be questioned. The construction of the wealth index for this study was based on a limited number of asset variables.

\section{Conclusion}

The results reveals that the use of smokeless tobacco individually are strongly associated with social status (e.g., low socioeconomic status, less education) in Bangladesh, indicating an important association between smokeless tobacco use and social determinants. Findings from the study indicate that female respondents having less education and wealth are predictors of smokeless tobacco use. Smokeless tobacco use increases as age increases. Implementation of tobacco control strategies drawn from the standards outlined in the WHO Framework Convention on Tobacco Control (FCTC) and WHO MPOWER could have benefits in reducing smokeless tobacco use and preventing smokeless tobacco related diseases.

\section{Acknowledgement} Group.

The authors would like to acknowledge the members of the GATS Collaborative

\section{References}

1. Ravenholt RT (1990) Tobacco's global death march. Population and Development Review 16: 213-240.

2. World Health Organization (2008) WHO report on the global tobacco epidemic, 2008: The MPOWER package. Geneva: World Health Organization.

3. Barkat A, Chowdhury AU, Nargis N, Rahman M, Khan MS, et al. (2012) The Economics of Tobacco and Tobacco Taxation in Bangladesh. Paris: International Union against Tuberculosis and Lung Disease.

4. Begum M, Sultana P (2017) Current Pattern of Product Specific Smokeless Tobacco Use in Bangladesh. J Biom Biostat 8: 362.
5. Aziz S, Choudhury T, Huque N (2015) Tobacco Use in Rural Bangladesh Socio-Demographic Characteristics, Self Rated Health and Diseases. Public Health Res 5: 198-205.

6. Choudhury K, Hanifi SMA, Mahmood SS, Bhuiya A (2007) Sociodemographic Characteristics of Tobacco Consumers in a Rural Area of Bangladesh. J Health Popul Nutr 25: 456-464.

7. Hossain S, Ahmed F, Islam R, Sikder T, et al. (2017) Prevalence of Tobacco Smoking and Factors Associated with the Initiation of Smoking among University Students in Dhaka, Bangladesh. Cent Asian J Glob Health 6: 244.

8. Khan NR, Mahmood AR (2015) Pattern of tobacco consumption and related factors among the people residing in a rural area. Bangladesh Med J 44: 32-37.

9. Khan MH, Khan A, Kraemer A, Mori M (2009) Prevalence and correlates of smoking among urban adult men in Bangladesh: slum versus non-slum comparison. BMC Public Health 9: 149.

10. Palipudi KM, Sinha DN, Choudhury S, Zaman MM, Asma S (2012) Predictors of tobacco smoking and smokeless tobacco use among adults in Bangladesh. Indian J Cancer 49: 387-392.

11. Rahman MM, Karim MJ, Ahmad SA, Suhaili MR, Ahmad SNW (2011) Prevalence and Determinants of Smoking Behaviour among the Secondary School Teachers in Bangladesh. International Journal of Public Health Research Special Issue, pp: 25-32.

12. Rahman MS, Mondal NI, Islam MR, Rahman MM, Hoque MN, et al. (2015) Determinant factors of tobacco use among ever-married men in Bangladesh. Drug Healthc Patient Saf 7: 77-85.

13. Abdullah AS, Driezen P, Ruthbah UH, Nargis N, Quah ACK, et al. (2014) Patterns and Predictors of Smokeless Tobacco Use among Adults in Bangladesh: Findings from the International Tobacco Control (ITC) Bangladesh Survey. PLoS ONE 9: e101934.

14. Hossain MS, Kypri K, Rahman B, Arsian I, Akter S (2014) Prevalence and correlates of Smokeless Tobacco Consumption among Married Women in Rural Bangladesh. PLoS ONE 9: e84470.

15. Global Adult Collaborative Group (2010) Global Adult Tobacco Survey (GATS) Quality assurance, guidelines and documentation, version 2.0.

16. Giovino GA, Mirza SA, Samet JM, Gupta PC, GATS Collaborative Group, et al. (2012) Tobacco use in 3 billion individuals from 16 countries: an analysis of nationally representative cross-sectional household surveys. Lancet 380 668-679.

17. Kalsbeek WD, Bowling JM, Hsia J, (2012) The Global Adult Tobacco Survey (GATS): Sample design and related methods, pp: 30

18. Sultana P, Akter S, Rahman MM, Alam MS (2015) Prevalence and Predictors of Current Tobacco Smoking in Bangladesh. J Biostat Biomet Appli 1: 102

19. WHO (2009) Global adult tobacco survey (GATS): Bangladesh. World Health Organization 2009

20. Khan MHR, Shaw JEH (2011) Multilevel Logistic Regression Analysis Applied to Binary Contraceptive Prevalence Data. J Data Sci 9: 93-110.

21. Krull JL, MacKinnon DP (2001) Multilevel Modeling of Individual and Group Level Mediated Effects, Multivariate Behav Res 36: 249-277.

22. Hosmer DW, Lemeshow S (2000) Applied Logistic Regression (2ndedn), Hoboken: Wiley, pp: 1-392.

23. Global Adult Tobacco Survey Collaborative Group (2010) Global Adult Tobacco Survey (GATS) Available at: http://www.who.int/tobacco/surveillance/survey/ gats/ en/ (Accessed on 18 August 2012). 